\title{
Patrimonialización de Áreas Naturales: prácticas vulnerables en las Reservas de Biosfera de Argentina y Brasil
}

\author{
Virginia Martins Fonseca 1 \\ Roberto Nicolas Bustos Cara ${ }^{2}$
}

\begin{abstract}
Resumen: Fue adoptado como el objetivo de investigación comprender cómo se configura el reconocimiento de los territorios naturales bajo la perspectiva del patrimonio internacional, desde la contextualización de presupuestos teóricos y documentales. Se identificaron tres influencias relevantes como resultados, en términos de perspectivas teóricas, a saber: "orden ambiental internacional"; "patrimonialización del territorio" y; "valoración turística". Como presupuestos documentales, se contextualizaron las realidades tanto de la Reserva de la Biosfera Norpatagónica Andina (Argentina) como de la Reserva de la Biosfera Serra do Espinhaço (Brasil), lo que mostró que tales procesos de internacionalización de áreas naturales protegidas son muy fragilizados en cuanto al real involucramiento de la población local para favorecer el debate legítimo sobre cuáles serían las posibilidades de integración del "hombre en la naturaleza" como efectiva estrategia de una ecología política.

Palabras-clave: patrimonio natural; intereses socioeconómicos; discursos globales; prácticas locales.
\end{abstract}

\section{Patrimonialização em Áreas Naturais: práticas vulneráveis nas Reservas de Biosfera de Argentina e Brasil}

Resumo: Adotou-se como objetivo de pesquisa compreender como o reconhecimento de territórios naturais se configura sob a ótica de patrimônio internacional, a partir da contextualização de pressupostos teóricos e documentais. Identificou-se como resultados, quanto as perspectivas teóricas, três relevantes influencias, a saber: "ordem ambiental internacional"; "patrimonialização do território" e; "valorização turística". Como pressupostos documentais, foram contextualizadas as realidades tanto da Reserva de Biosfera Andino Norpatagónica (Argentina) como Reserva de Biosfera Serra do Espinhaço (Brasil), que evidenciaram que tais processos de internacionalização de áreas naturais protegidas estão muito fragilizados quanto ao real envolvimento da população local para favorecer o debate legitimo de como seriam as possibilidades de integração do "homem com a natureza" como efetiva estratégia por uma ecologia política.

Palavras-chave: patrimonio natural; interesses socioeconomicos; discursos globais; práticas locais.

\section{Patrimonialization in Natural Areas: vulnerable practices in to the Biosphere Reserves of Argentina and Brazil}

\begin{abstract}
It was adopted as the research objective to understand how the recognition of natural territories is configured under the perspective of international heritage, from the contextualization of theoretical and documentary budgets. Three relevant influences were identified as results, in terms of theoretical perspectives, namely: "international environmental order"; "patrimonialization of the territory" and; "tourist valorization". As documentary budgets, the realities of both the Andean Norpatagonic Biosphere Reserve (Argentina) and the Serra do Espinhaço Biosphere Reserve (Brazil) were contextualized, which showed that such internationalization processes of protected natural areas are very fragile as to the real involvement of the local population to favor the legitimate debate on what would be the possibilities of integration of "man in nature" as an effective strategy of a political ecology.
\end{abstract}

Keywords: natural heritage; socio-economic interests; global speeches; local practices. (c) (i) (\$) $\Theta$

DOI: https://doi.org/10.26512/patryter.v4i7.25521

Como citar este artigo: Martins Fonseca, V.; Bustos Cara, R. N. (2021). Patrimonialización de Áreas Naturales: prácticas vulnerables en las Reservas de Biosfera de Argentina y Brasil. PatryTer-Revista Latinoamericana e Caribenha de Geografia e Humanidades, 4 (7), 44-62. DOI: https:/ /doi.org/10.26512/patryter.v4i7.25521

Recebido: 04 de dezembro de 2019. Aceite: 12 de maio de 2020. Publicado: 01 de março de 2021.

${ }^{1}$ Profesora de la Universidade Federal dos Vales do Jequitinhonha e Mucuri - UFVJM. Doctora en Geografía por la Universidad Nacional del Sur. ORCID: https://orcid.org/0000-0002-1629-8812. E-mail: profvirginiaufvim@gmail.com

${ }_{2}$ Profesor de la Universidad Nacional del Sur. Doctor en Geografía por la Universidad de Bordeaux III. ORCID: https://orcid.org/0000-0001-9205-8792.E-mail: usbustos@gmail.com 
Virginia Martins Fonseca;

Roberto Nicolas Bustos Cara
Patrimonialización de Áreas Naturales: prácticas vulnerables en las Reservas de Biosfera de Argentina y Brasil

\section{Introduccion $^{\mathrm{i}}$}

La perspectiva histórica de las áreas protegidas [AP] en el ámbito mundial suscita algunas paradojas teóricas y prácticas como el término "patrimonialización" en tanto instrumento de protección del patrimonio natural. Esto permite observar que la idea de patrimonialización está íntimamente relacionada con los principios de la institucionalización por medio del reconocimiento de determinado bien, incluso en la esfera internacional, como aquellos mencionados por la United Nations Educational, Scientific and Cultural Organization [UNESCO].

Muchos críticos buscan una comprensión cabal acerca del término "patrimonialización" y, en este sentido, cabe aclarar que el término patrimonio, a pesar del sentido universal de "algo" que pertenece a todos, que todos valoran, que todos son responsables de cuidar, éste también debe ser considerado en el sentido de sus vínculos con el pasado, lo que implica un compromiso con las generaciones futuras. Así que es la propia sociedad quien determina lo que puede ser considerado como patrimonio, según el contexto y el momento histórico-cultural-ambiental, ya que el ser humano es demasiado dinámico como para cristalizar su experiencia. Para Da Matta (1981), tomando en cuenta el principal objetivo de la antropología, debe comprenderse que la cultura es inherente a la experiencia humana y por lo tanto portadora de sentido y de significado, y con capacidad de responder, de forma siempre original, a las relaciones de causalidad entre distintas dimensiones de la experiencia (biológica, social, cultural). Así, "la cultura como producto de la sociedad también ayuda a elaborarla, tanto porque está vinculada al amparo de concepciones y de formas de organización y de vida, como por estar vinculada a la transformación de ésta" (Santos, 1984, p. 65).

El patrimonio inicialmente estuvo vinculado a la idea de cultura, desde mediados del siglo XX, con la publicación de la convención de La Haya (UNESCO, 1954). Junto a la definición de patrimonio cultural surge la comprensión ( $\mathrm{y}$ preocupación) de salvaguardar el patrimonio natural considerando, en especial, aquel con valor excepcional en términos de ciencia, conservación y belleza de los paisajes naturales. Sobre esta base se desarrolla el proceso de patrimonialización de áreas naturales.

El presente estudio adopta como marco metodológico el estudio de caso (Yin, 2010), como técnica de recolección de datos: la documentación, registro de archivos, observación directa y artefactos físicos; y para la interpretación de los datos obtenidos, el análisis de contenido (Bardin, 2011) que objetiva una comprensión hermenéutica controlada, basada en inferencias. Específicamente fue realizado el análisis de contenido en publicaciones provenientes de diferentes fuentes internacionales y nacionales (Argentina y Brasil), desde organismos gubernamentales; organizaciones extranjeras; legislaciones; trabajos técnicos y producciones científicas. De manera general, el análisis de los discursos globales está relacionado a la perspectiva político-institucional en cuanto el análisis de las prácticas locales está relacionado a la perspectiva técnico-científica. Las excepciones están a cargo de las publicaciones gubernamentales específicas del local.

Según Moraes (1999), el contexto debe de ser reconstruido por el investigador $y$, de cierto modo, el análisis de contenido es una interpretación personal por parte del investigador a la percepción que tiene de los datos y, como toda lectura se constituye de una interpretación, no es posible una lectura neutra.

\section{Presupuestos pertinentes relacionados a las Reservas de Biosfera [RB]}

El proceso de patrimonialización surge como una construcción social por definición, que impacta en las modalidades de reconocimiento, los procedimientos de salvaguarda, conservación y valorización para determinada selección patrimonial según criterios económicos, ideológicos, culturales y políticos (Martins Fonseca, 2018). Por tanto, aun comprendiendo la importancia de tal proceso, no se puede ignorar la idea presentada por Prats (2005), al argumentar que los procesos de activación patrimonial (o puesta en valor) dependen fundamentalmente de los poderes políticos, por los cuales deben negociar con otros poderes, entre ellos, la propia sociedad.
¿Qué significa, entonces activar un repertorio patrimonial? Escoger determinados referentes del pool y exponerlos de una u otra forma. Evidentemente esto equivale a articular un discurso que quedará avalado por la sacralidad de los referentes que se destaquen, de la importancia relativa que se les otorgue, de su interrelación (es decir del orden del conjunto que integren) y del contexto (en un proceso no exento, a veces, de burdas pretensiones de reducción de los simbolos a signos). Es bien claro, pues, que ninguna activación patrimonial, ninguna, de ningún tipo, es neutral o inocente, sean conscientes o no de ello to correspondientes gestores del patrimonio. (Prats, 1998, pp.68). 
Virginia Martins Fonseca;

Roberto Nicolas Bustos Cara
Patrimonialización de Áreas Naturales: prácticas vulnerables en las Reservas de Biosfera de Argentina y Brasil
Contextualizando tal perspectiva para la patrimonialización de bienes de carácter natural, y considerando criterios económicos, se desprende que la puesta en valor favorece y fortalece la promoción del turismo en dichas áreas protegidas, según intereses mayoritariamente externos y con vistas a impulsar determinados destinos en el escenario turístico. Muchas veces la excepcionalidad adquiere un reconocimiento internacional. Para Bertoncello (2010, p. 39) es donde surge otra tensión teórica y empírica: cuando un patrimonio es instituido, implica anular otros posibles patrimonios, logrando generar un movimiento "contra-patrimonio".

Así, el valor patrimonial tiene correlación con situaciones de poder que son consolidados en relación con la identidad que lo sustenta; por este motivo es difícil ignorar la influencia que la actividad turística genera en este contexto, frente a la paradoja: ¿patrimonio por sus propiedades o patrimonio para ser comercializado? El turismo, en este contexto, subvierte la lógica del patrimonio, pues lo convierte en producto, aunque diferenciado, pero un producto más.

De acuerdo con esto, apuntes interesantes de reciente estudio de Bertoncello y Troncoso (2018), complementan tales relaciones entre turismo, naturaleza y patrimonio, donde se analizó que en los nuevos destinos relacionados a los parques nacionales de Argentina se valora una naturaleza "diferente". Para los autores, se reconocen otras prácticas importantes a partir de un perfil distinto de turistas que posee alto compromiso y conocimiento de las especificidades de una naturaleza que debe ser valorada en sí misma y, por lo tanto, "dan lugar a prácticas de exploración activas, $[\ldots]$, y que son particularmente valoradas por usuarios no masivos" que adoptan, preocupados con la posibilidad de escasez y riesgos de desaparición de esta naturaleza, uno "carácter perentorio de visitarla" puesto que se configura como "una forma de incentivar su protección y, de este modo, los objetivos de preservación y turísticos parecen coincidir en una relación virtuosa" y "a través del turismo, esta naturaleza 'prístina' preservada queda sujeta a estrategias utilitarias de uso y apropiación, habilitando nuevas formas de valorización social (y destacadamente, económica) del patrimonio natural" (Bertoncello y Troncoso, 2018, p.90-91).

En este sentido, es imprescindible retomar otro término asociado al turismo: el territorio. Todos son términos interconectados, aunque se observa que tales términos están adquiriendo, cada vez más un uso aleatorio, convencional o abstracto, considerando el discurso de la turistificación de los espacios geográficos, calificada como una de las principales alternativas socio-económicas contemporáneas. En este sentido, para Martins Fonseca (2018), siendo el territorio la base del desarrollo del turismo, éste deberá ser pensado en términos relacionales (tanto a partir de la demanda, como de la oferta turística), lo que implica tomar en cuenta los conflictos que emergen en tales relaciones. Por lo tanto, hay que considerar la relación de subordinación existente en esta situación, pues es la demanda la que busca en determinado destino lo que no encuentra en su lugar de origen; esto se transforma en una verdad absoluta: la valorización del lugar es externa, porque es el turista quien define lo que debe ser valorizado.

En este sentido, resulta de interés el planteo de J. Urry (1996), quien señala la necesidad de pensar el turismo no sólo desde el lugar de destino, sino también considerando los lugares de origen; lugares de origen y de destino estarian articulados por los turistas, que llevan adelante esta práctica en el marco de sus prácticas cotidianas (inscriptas, a su vez, en dinámicas sociales más generales). Así como ha sido usual que se reconozcan las condiciones de vida en las sociedades modernas occidentales (altamente urbanizadas, con mercados de trabajo asociados a una clara diferenciación del tiempo de trabajo y del tiempo libre, etc.) como las que impulsan el crecimiento del turismo, comienza a verse también que es en relación con estas sociedades de origen que se definen aquellos rasgos que, propios de otros lugares, serán concebidos y valorizados como atractivos turísticos. En definitiva, no importaría cuán destacados, únicos o excepcionales sean los rasgos de un determinado lugar de destino, dado que sólo se valorizarán como atractivos turísticos si logran coincidir con $-y$ responder alas demandas presentes en las sociedades de origen de los turistas. En consecuencia, la valorización de un lugar como destino turístico no se produciría sólo por los rasgos que le son propios ni exclusivamente por la lógica de la sociedad que habita ese lugar. (Almirón, Bertoncello \& Troncoso, 2006, pp. 107)

De este modo el turismo se ubica en la dimensión simbólica, en tanto distinción social, porque el turista refuerza la estructura social y económica, pues al retornar a su lugar de origen influye sobre el medio en que vive según la experiencia obtenida, reforzando las relaciones de poder en la sociedad moderna. Por lo tanto, el atractivo puede ser auténtico si el entendimiento de autenticidad del turista lo define como legítimo. 
Virginia Martins Fonseca;

Roberto Nicolas Bustos Cara
Patrimonialización de Áreas Naturales: prácticas vulnerables en las Reservas de Biosfera de Argentina y Brasil
No se puede ignorar que los destinos también participan de este proceso activamente, principalmente en cuanto a los impactos producidos, sean positivos o negativos. El destino posee cualidades, en principio, como aspecto inherente a cualquier lugar, pero se distingue en cuanto a la forma como su imagen es percibida y consolidada, frente a múltiples intereses. Así, dentro de los diversos conflictos que el turismo genera en determinada localidad, se destacan las tensiones del turismo en la venta del territorio y del patrimonio turístico como diferencial de sustentabilidad, cuando en la realidad no lo es, pues se trata, una vez más, de una reproducción capitalista, toda vez que es el turismo-turista quien define lo que es o no estético, por cuanto tiempo lo será y donde está, implicando intereses económicos asociados a selección, jerarquización y lectura de los procesos de construcción de las dimensiones simbólicas significativas para ese periodo.

[...] el proceso de valorización turística del patrimonio de un lugar estará fuertemente condicionado por la demanda turística, externa al lugar de destino turístico y, por lo tanto, la selección del patrimonio a ser valorizado turísticamente - al igual que la modalidad que esta valorización adopte - estarán en función de esta demanda.[...] La posibilidad de seleccionar, de un amplio acervo patrimonial, aquellos objetos o rasgos que sean de interés para la actividad turística representa, por otra parte, una nueva oportunidad de articulación del lugar en un territorio turístico más amplio, abriendo nuevas posibilidades. Se asiste hoy a una fuerte competencia entre lugares por ser elegidos como destinos turísticos, no sólo por los turistas sino también por el capital involucrado en las actividades económicas vinculadas al turismo. Es aquí donde la "presencia" de patrimonio cobra pleno sentido, en la medida en que carga al lugar donde se encuentra, de cualidades distintivas que le permiten colocarse en un "mercado de lugares (destinos) turísticos" desde una posición privilegiada, apropiándose de la carga simbólica y del prestigio que el patrimonio otorga a sus atractivos turísticos. [...] el éxito que los actores sociales puedan tener en activar su patrimonio deja ya de tener consecuencias sólo culturales o simbólicas para, a través de la valorización turística de este patrimonio, inscribirse plenamente en la lógica económica. (Almirón et al., 2006, pp. 113-114)

Existe también, según Di Meo (2014), una territorialización del patrimonio, o mejor aún, una patrimonialización del territorio, puesto que cada vez más espacios significativos externos han sido reconocidos como tal, ya que tales espacios no se transforman necesariamente en bienes comunes y públicos en cuanto objetos sistemáticos de apropiación y de uso privado. Tal afirmación se justifica frente al reconocimiento de ciudades y comunidades enteras, paisajes y áreas ambientales "carentes" de protección o conservación, que deben ser consideradas como patrimonio vivido, representado y no-jurídico, en fajas enteras de territorio con función simbólica colectiva.

Costa (2014) también contribuyó con la presentación del concepto "patrimonialización global" en qué determina, de manera puntual y asertiva, las contradicciones entre la "preservación" e mercantilización de los lugares o de los objetos, ya que:

A patrimonialização global é produto $e$ representante da transformação da própria história dos lugares em história mundial, não de uma história mundial metafísica, mas de ações materiais que rebatem sobre territórios que foram conquistados, dominados e revalorados ao longo do tempo, formando cidades classificadas pelas atividades destinadas ao exterior (Costa, 2014, p.244).

Para dilucidar tal enunciado, nada más oportuno que el ejemplo de la UNESCO donde se propone promover la identificación, la protección y la preservación del patrimonio, estableciendo que ciertos lugares de la Tierra con un "Valor Universal Excepcional" deben pertenecer como patrimonio común de la humanidad. Tal objetivo está incorporado en el tratado internacional denominado Convención sobre la Protección del Patrimonio Mundial Cultural y Natural, aprobada por la UNESCO en 1972. Actualmente (datos de diciembre de 2019), 190 países han ratificado la Convención y, la Lista del Patrimonio Mundial incluye un total de 1.121 sitios (869 culturales, 213 naturales y 39 mixtos) en 167 Estados Partes.

Resultan interesantes las reflexiones de Scifoni (2004) acerca la Lista de Patrimonio Mundial de la UNESCO, donde la autora constata que las localidades consagradas como tales, no necesariamente se constituyen solamente por intermedio de un instrumento técnico, científico, neutro e imparcial, visto que revela un carácter proprio de relaciones de desigualdad presentes en el mundo. En este sentido, Scifoni (2004) considera que el proceso de patrimonialización debe ser interpretado no solamente a partir de criterios técnicos, sino también a la luz de las contradicciones, conflictos y articulaciones que rigen el cuadro de las relaciones internacionales. 
Figura 1 - Relación percentil de patrimonios mundiales

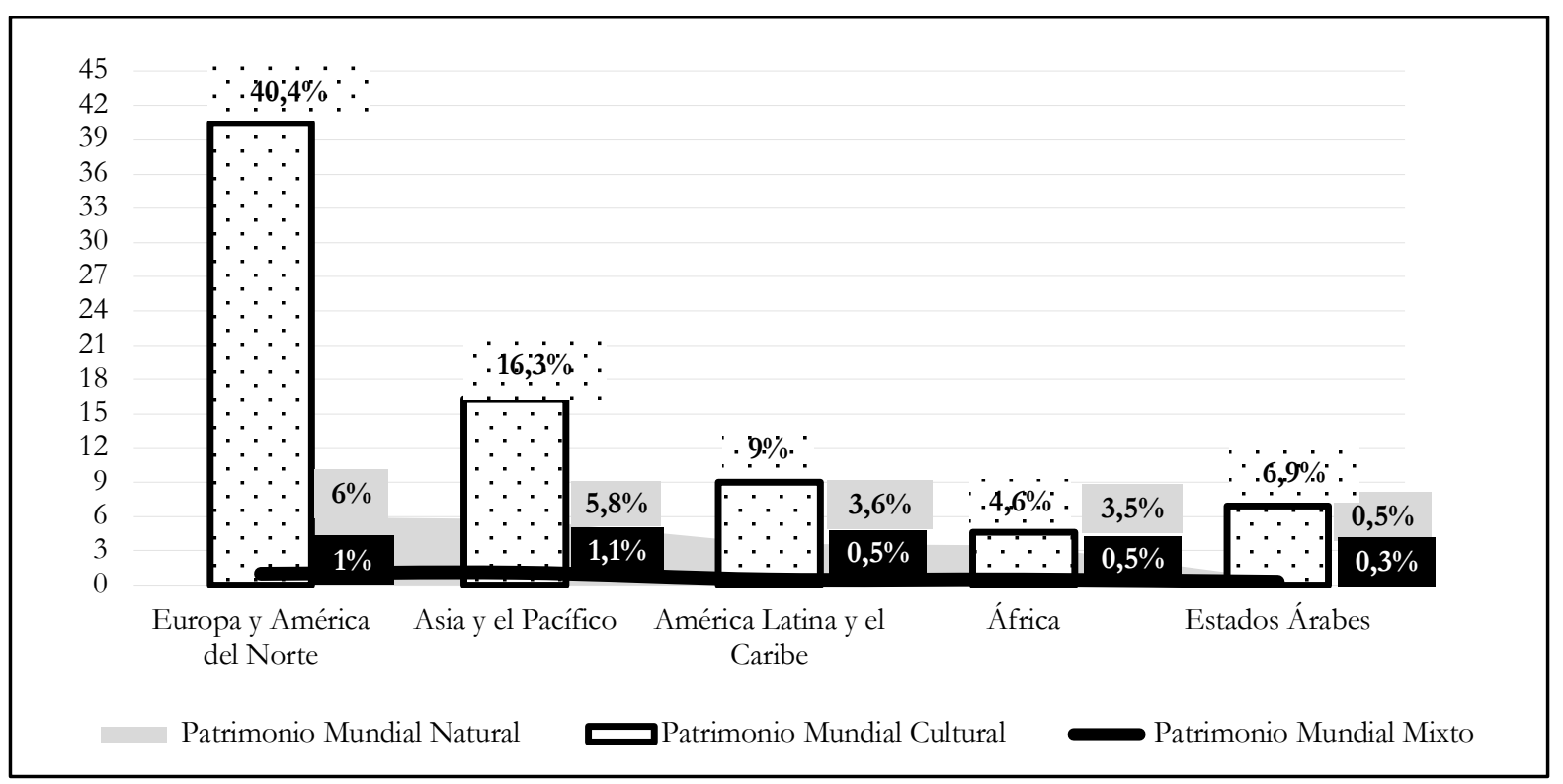

Fuente: elaborado por Martins Fonseca (2018), actualizado a partir de datos de la UNESCO (2019), actualizado en esta publicación.

Tal controversia surge en otro estudio de la misma autora (Scifoni, 2003), en el cual analiza los criterios para el reconocimiento de bienes y áreas como patrimonio mundial, interpretando aspectos interesantes acerca de las cuestiones de hegemonía política-económica y de soberanía nacional como elementos claves de interpretación; destacando cómo las relaciones de poder influyen en las tomas de decisión, selección y en la construcción del discurso del patrimonio. Entonces es posible comprender, lo expresado en la Figura 1 que presenta la relación percentil de patrimonios mundiales cultural, natural y mixto, constatando datos que fueron actualizados ii . Todos los continentes mantienen más patrimonio mundial cultural reconocido que patrimonio mundial natural (en términos cuantitativos). Europa y América del Norte, seguida de Asia y el Pacífico, mantienen el mayor número de sitios patrimoniales mundiales reconocidos — cualquiera sea: Cultural, Natural y Mixtos, como ya apuntaban los estudios de Scifoni (2003)—.

Todavía, la zona de África se destaca como el continente que presenta una relación patrimonio cultural versus patrimonio natural menos desigual. Tales porcentajes son seguidos por América Latina y el Caribe que presentan un $27 \%$ de su total caracterizado como patrimonio natural.

Pero, cuando nos referimos a patrimonialización del territorio, notamos que el área territorial de patrimonio mundial cultural representa menos de $2 \%$, en cuanto el patrimonio mundial natural es cuasi $78 \%$ y el patrimonio mundial mixto de, aproximadamente, $20 \%$, de todo patrimonio mundial reconocido por UNESCO (Figura 2).

Asia y el Pacífico se destacan por presentar casi $40 \%$ del área territorial del total de patrimonio mundial de la UNESCO, en lo cual 37,9\% es natural. Seguido están los continentes de Europa y América del Norte presentando porcentual de más de 30\%.

Siguiendo el razonamiento de Scifoni (2003, p. 9), se propone la idea de "orden ambiental internacional" para justificar las influencias norteamericanas, europeas y niponas en la determinación de tales patrimonios. Esto permitiría suavizar la imagen que algunos países de estos continentes reflejan frente a determinados conflictos internacionales, y considerando el apoyo político, institucional y económico a la UNESCO, en determinados momentos de la historia contemporánea.

El proceso de reconocimiento de un bien, y su consecuente inclusión en la Lista de Patrimonio Mundial, es complejo y riguroso, considerando que, en primera instancia, el país deber formar parte de la Convención para solicitar la inclusión en el listado, y adjuntar toda la documentación de apoyo para el análisis. Deberá asimismo demostrar el valor universal y las condiciones de integridad, presentar un plan de gestión para el área y los sitios, que supuestamente cuentan con una protección jurídica adecuada. 
Figura 2 - Relación percentil de la patrimonialización territorial de la UNESCO

\begin{tabular}{|l|c|c|c|c|}
\hline \multicolumn{1}{|c|}{ Continentes } & $\begin{array}{c}\text { Patrimonio } \\
\text { Mundial Natural }\end{array}$ & $\begin{array}{c}\text { Patrimonio } \\
\text { Mundial Mixto }\end{array}$ & $\begin{array}{c}\text { Patrimonio } \\
\text { Mundial Cultural }\end{array}$ & Total \\
\hline Europa y América del Norte & $17,6 \%$ & $14 \%$ & $0,6 \%$ & $32,2 \%$ \\
\hline Asia y el Pacífico & $37,9 \%$ & $1,7 \%$ & $0,4 \%$ & $40 \%$ \\
\hline América Latina y el Caribe & $8,5 \%$ & $0,3 \%$ & $0,3 \%$ & $9,1 \%$ \\
\hline África & $13,2 \%$ & $1,6 \%$ & $0,3 \%$ & $15,1 \%$ \\
\hline Estados Árabes & $0,7 \%$ & $2,8 \%$ & $0,1 \%$ & $3,6 \%$ \\
\hline Total & $\mathbf{7 7 , 9 \%}$ & $\mathbf{2 0 , 4 \%}$ & $\mathbf{1 , 7 \%}$ & $\mathbf{1 0 0} \%$ \\
\hline
\end{tabular}

Fuente: elaborado por Martins Fonseca (2018), actualizado a partir de datos de UNESCO (2019), actualizado en esta publicación.

Figura 3 - Relación Reservas de Biosfera y proporciones evaluadas.

\begin{tabular}{|l|c|c|c|}
\hline \multicolumn{1}{|c|}{ Continentes } & RB & Países & Área Territorial \\
\hline Europa y América del Norte & $45,1 \%$ & $30 \%$ & $25,2 \%$ \\
\hline Asia y el Pacífico & $21,2 \%$ & $20 \%$ & $11 \%$ \\
\hline América Latina y el Caribe & $18,7 \%$ & $17,5 \%$ & $36,6 \%$ \\
\hline África & $10,5 \%$ & $23,3 \%$ & $7 \%$ \\
\hline Estados Árabes & $4,5 \%$ & $9,2 \%$ & $20,2 \%$ \\
\hline
\end{tabular}

Fuente: elaborado por Martins Fonseca (2018), actualizado a partir de datos de la UNESCO \& MaB (2019), actualizado en esta publicación.

A continuación, el Centro de Patrimonio Mundial verifica si la proposición está completa, en cuanto el Consejo Internacional de Monumentos y Sitios [ICOMOS] o la Unión Internacional para la Conservación de la Naturaleza [UICN], respectivamente cultural o natural, con el objeto de avalar técnicamente el valor universal del bien. En este sentido, la Oficina del Patrimonio Mundial estudia las opiniones de los árbitros y, finalmente, el Comité del Patrimonio Mundial, compuesto por 21 representantes de los países-parte, deliberaran por la inclusión o no en la Lista.

Similar al proceso de reconocimiento del Patrimonio Mundial, las Reservas de Biósfera [RB] son seleccionadas en base a parámetros científicos que van más allá del objetivo de protección, pues aspiran a desarrollar un modelo de gestión inclusivo de los Gobiernos y la sociedad local-regional con el objeto de alcanzar tres funciones prioritariasiii. La selección de las Reservas se hace a partir de las propuestas de los Estados Miembros de la UNESCO, seguida de evaluación por el Comité de Especialistas que asesora el Programa Man and the Biosphere [MaB]. Actualmente son 701 reservas de biósfera en 124 países (datos de diciembre de 2019). La distribución de tales patrimonios de biodiversidad planetaria tiene similares proporciones a los patrimonios mundiales, como se observa en la Figura 3, que representa la relación percentil del total de Reservas de Biósfera, la proporción de países involucrados en ámbito mundial y el área territorial de los sitios RB, según continentes.

Se observa que, en términos cuantitativos, más de $45 \%$ de las RB mundiales corresponden a Europa y América del Norte. En términos de percentil de países que poseen RB, África presenta un aporte cuantitativo significativo, alrededor de $23 \%$ de los países del mundo, aunque se ubique en cuarto lugar en el ranking en el mismo término numérico de RB comparado entre continentes. Respecto al tema del proceso de patrimonialización del territorio, teniendo en cuenta que las RB involucran significativas superficies territoriales $y$ marinas, notamos que es en América Latina y el Caribe donde se concentran las mayores extensiones territoriales reconocidas como tal en todo el mundo. 
Virginia Martins Fonseca;

Roberto Nicolas Bustos Cara

Se puede afirmar, aún, que casi todos los sitios reconocidos tanto como Reserva de Biosfera como Patrimonio Mundial Natural presentan doble protección, pues para ser considerados en el ámbito internacional deben constituir patrimonio en el ámbito nacional, lo que implica mantener la prioridad de selección de determinadas áreas según diversos intereses y procesos de articulación entre los actores involucrados en dicho ámbito. Además, si bien Brasil se destaca en términos de extensión territorial protegida, Argentina lo supera en términos cuantitativos en cuanto al tema de áreas reconocidas internacionalmente, lo que sugiere mayor articulación político institucional en el escenario mundial para el reconocimiento de ecorregiones.

A modo de aclaración, en el caso de las Reservas de Biosfera, existe interés especial en explicitar algunos aspectos de las mismas, tanto en Argentina como en Brasil. Por ejemplo, cuando se analiza el primer acta del Consejo Internacional de Coordinación del Programa el Hombre y la Biosfera, ambos países son designados como integrantes durante el periodo de 1971-1972, dentro de 26 Estados Miembros elegidos, previo informe del Comité de Candidatura, publicado en la $31^{a}$ sesión plenaria de noviembre de 1970. El interés especial por el tema de las RB se justifica por el carácter innovador del programa que, en plena década del 1970, tiene como objetivo general:

Proporcionar los conocimientos fundamentales de ciencias naturales y de ciencias sociales necesarios para la utilización racional y la conservación de los recursos de la biosfera y para el mejoramiento de la relación global entre el hombre y el medio, así como para predecir las consecuencias de las acciones de hoy sobre el mundo de mañana, aumentando asi la capacidad del hombre para ordenar eficazmente los recursos naturales de la biosfera (UNESCO \& $\mathrm{MaB}, 1971$, pp. 7-8) [lo destacado en la cita es nuestro].

Si bien en el transcurso del programa $\mathrm{MaB}$ hubo cambios, nunca se suprimió la importancia de "una mayor participación de la población local y su desarrollo socioeconómico" tomando como referencia el Primer Plan de Acción de las Reservas de Biosfera, elaborado en el 1ero Congreso Internacional de Reservas de Biosfera en Minsk, en 1983. Una de las características de este plan es que las RB son consideradas AP bajo un matiz antrópico, como lugares de demostración de relaciones más armónicas:
Patrimonialización de Áreas Naturales: prácticas vulnerables en las Reservas de Biosfera de Argentina y Brasil b) Las personas deben considerarse parte integrante de una reserva de biosfera. La población humana constituye un componente esencial del paisaje y sus actividades son primordiales para la conservación de ésta a largo plazo y para que sus utilizaciones sean compatibles. Las personas y sus actividades no están excluidas de una $R B$, sino que por el contrario se las alienta a participar en su gestión, con lo que se logra una mayor aceptación social en las actividades de conservación. (UNESCO \& MaB, 1985, pp. 42)

En marzo de 1995 en Sevilla, fue realizado el 2o Congreso Internacional sobre Reservas de Biosfera, pese a los problemas y limitaciones que planteaba la aplicación del concepto. Allí fueron identificadas 10 directrices para sustentar la nueva estrategia en la cual, 4 presentan conexión directa entre el hombre y el medio. (UNESCO \& MaB, 1996)

1. tener más en cuenta la dimensión humana del concepto RB, para reforzar los vínculos entre la diversidad cultural y la biológica, conservando el conocimiento tradicional y los recursos genéticos, en que el desarrollo sostenible debe ser reconocido y estimulado;

2. propiciar la administración de la RB como un "pacto" entre la comunidad local y la sociedad en conjunto, lo que implica una administración más abierta, evolutiva y adaptativa, garantizando que tanto la RB como sus comunidades locales se encuentren en mejores condiciones para responder a las presiones externas de índole política, económica y social;

3. agrupar a los actores y sectores interesados en una tarea común que permita promover las $\mathrm{RB}$ en el plano local y en las redes, asimismo la información debe circular libremente entre todas las partes involucradas y;

4. las RB deben ser utilizadas para ampliar el conocimiento de las relaciones entre la humanidad y el medio, mediante programas de divulgación, información y educación en una perspectiva a largo plazo e intergeneracional.

El 3er Congreso Mundial de Reservas de la Biósfera, realizado en Madrid durante febrero de 2008 (UNESCO \& MaB, 2008), definió cuatro áreas principales de acción, con 31 objetivos y 65 acciones críticas para lograr la visión y la misión del programa MaB. Frente a la ampliación de los objetivos, ganaron 
Virginia Martins Fonseca;

Roberto Nicolas Bustos Cara
Patrimonialización de Áreas Naturales: prácticas vulnerables en las Reservas de Biosfera de Argentina y Brasil relevancia acciones pautadas en la difusión de informaciones de la $\mathrm{RB}$ y captación de recursos financieros complementarios para el desarrollo de distintas acciones orientadas a la investigación. Aunque la importancia de la participación y protagonismo de las comunidades estaban claramente expresadas en la definición y gestión de las RB, se observa que éstas no son tan explícitas en el documento final del evento; como en ediciones anteriores del congreso, tal vez y justamente porque, aún después de más de 30 años de dicha estrategia, las RB se mantienen más en el discurso político-institucional que implementadas efectivamente como práctica cotidiana.

El 4o Congreso Mundial de Reservas se llevó a cabo en marzo de 2016 en Lima y, retomó en el discurso, incluso como área de acción estratégica, el tema "La gobernanza efectiva del Programa MaB y la Red Mundial de Reservas de la Biosfera", aunque reconoce como ventaja técnica una mayor atención a la representación de los Estados Miembros en las reuniones del Consejo Internacional, olvida el real involucramiento de las comunidades en los procesos de gestión de tales territorios. En este sentido, parece evidente que los retos de las $\mathrm{RB}$ se establezcan en los países de una manera general, con una gran falta de compromiso del sector público para poner en práctica las directrices. Particularmente en lo que refiere a la necesidad de delegar el efectivo ejercicio de la gobernanza, no solo en la gestión de dichos territorios en el ámbito nacional, sino también en los consejos e instancias responsables locales, como legitimación en la práctica de tal discurso, donde efectivamente todo el proceso sea gestionado de manera participativa. Además, hay un desconocimiento en las propias regiones reconocidas como $\mathrm{RB}$ de que se trata dicho reconocimiento mundial. Saber de la existencia de una $\mathrm{RB}$ está relacionado exclusivamente al rol de los actores institucionales y académicos, responsables de la elaboración de todo el trámite de reconocimiento, de manera general. Por tanto, antes de llevar a cabo cualquier acción, es necesario la visibilización de la necesidad de dicho proceso y, posiblemente un nuevo debate para legitimar tal instancia, primero en la comunidad local y regional para, entonces, validar y poner en marcha las acciones necesarias tendientes a concretar el discurso de las RB, en el caso que tengan sentido y valor para las comunidades locales.

Es necesario aclarar que la intención no es cuestionar la relevancia ecológica y sociocultural, en el caso de tales procesos de patrimonialización de la naturaleza, pero sí se destaca concientización de la importancia de los mismos, dando la razón al documento base (la Convención del Patrimonio
Mundial), con pautas precisas para la identificación de los principios de preservación del patrimonio natural, a saber:

\section{[...] amenazados de destrucción, no sólo por las causas tradicionales de deterioro sino también por la evolución de la vida social y económica que las agrava con fenómenos de alteración o de destrucción aún más temibles [... que resulta] un empobrecimiento nefasto del patrimonio de todos los pueblos del mundo;}

[...] la protección de ese patrimonio a escala nacional es en muchos casos incompleto, dada la magnitud de los medios que requiere y la insuficiencia de los recursos económicos, científicos y técnicos del país en cuyo territorio se encuentra el bien que ha de ser protegido [...que puede ser amparada visto que] la Constitución de la Unesco estipula que la Organización ayudará a la conservación, al progreso y a la difusión del saber, velando por la conservación y la protección del patrimonio universal, y recomendando a los interesados las convenciones internacionales que sean necesarias para ese objeto;

[...] que ciertos bienes del patrimonio cultural y natural presentan un interés excepcional que exige se conserven como elementos del patrimonio mundial de la humanidad entera [... puesto que] ante la amplitud y la gravedad de los nuevos peligros que les amenazan, incumbe a la colectividad internacional entera participar en la protección del patrimonio cultural y natural de valor universal excepcional prestando una asistencia colectiva que sin reemplazar la acción del Estado interesado la complete eficazmente [...sugiere que] es indispensable adoptarpara ello nuevas disposiciones convencionales que establezcan un sistema eficaz. de protección colectiva del patrimonio cultural y natural de valor excepcional organizada de una manera permanente, y según métodos científicos y modernos. (UNESCO, 1972) [lo destacado en la cita es nuestro].

Aquello que puede diferenciar un sitio del Patrimonio Mundial, dentro de la diversidad de los sitios patrimoniales reconocidos a nivel nacional, suele ser el Valor Universal Excepcional que tenga peso para las Directrices Operativas de dicha Convención. Esto determina que la importancia (cultural y/o natural) sea tan extraordinaria que trascienda las fronteras nacionales y cobre importancia para las generaciones presentes y venideras de toda la humanidad, resultando en la necesidad de una protección permanente; por ello debe ser tratado con preocupación y con 
Virginia Martins Fonseca;

Roberto Nicolas Bustos Cara
Patrimonialización de Áreas Naturales: prácticas vulnerables en las Reservas de Biosfera de Argentina y Brasil responsabilidad común de la humanidad en términos de preservación. A decir, ideas altamente subjetivas y parciales, a pesar de la calidad del concepto.

Asimismo, en el concepto de responsabilidad común de la humanidad, en términos de acción, tales iniciativas deben abarcar la comprensión que el reconocimiento internacional no significa la sustitución del Estado en la preservación de su propio patrimonio identificado mundialmente. Cada país debe disponer de organismos vinculados al patrimonio como instrumentos legales, normativos y metodológicos, imprescindibles para el éxito de sus respectivas atribuciones, considerando la diversidad y variedad de los patrimonios en cualquier ámbito (local, regional, nacional, además del internacional).

Es de suponer que los actores institucionales involucrados, en mayor o menor grado, forman parte de la discusión, para producir consenso acerca de lo que debe ser el patrimonio cultural o natural, por lo tanto, lo que debe ser preservado o no, paradójicamente. Para ilustrar, ya que se refiere únicamente al ámbito de Argentina, es importante mencionar que Bustos y Pinassi (2017) evalúan el rol institucional desarrollado por las políticas públicas a escala nacional que involucran el proceso de patrimonialización en el país; los autores llevan a cabo un análisis de los Ministerios de Ambiente y Desarrollo Sustentable; de Cultura; de Turismo y Modernización de la Nación, donde se hace referencia a aquellos lineamientos asociados a la revitalización y custodia del patrimonio cultural y natural, ya sea de forma directa o indirecta.

In general terms, two particular characteristics of the public policies analyzed for these four bodies may be revealed: first of all, a non-integral treatment can be seen in the bandling of the resources, with a prevalence of strategies aimed either at the elements of nature or those derived from the actions of man, i.e., that in most cases, management is provided in only one sphere: the cultural or the natural, without considering the fact that both may make up a network of relationships in any given territory; and secondly, an unarticulated management between both governing bodies can be seen, and this is a relevant shortcoming, given that the components of territorial heritage require transversality in the knowledge and wisdom that allow their use andor preservation from an integral point view, and which not only articulates them as part of a space, but also includes the local population as participant in their development. (Bustos \& Mayoral, 2017, pp.287).
Este estudio evidencia las contradicciones en el territorio nacional, demandando análisis puntuales de las disputas de poder, presentes en la estructura institucional del poder ejecutivo de un país, donde determinados sectores tienen prioridades para inversión en el desarrollo de proyectos distintos. La tímida articulación entre las diferentes instancias no favorece una transversalidad de proyectos políticos gubernamentales, lo que podría generar resultados más productivos, deseados en todos los sectores. Sin duda, un desafío para otra investigación científica.

Es en el territorio nacional donde están las competencias económicas y político-institucionales. Sobre todo, entre localidades y regiones, se evidencia la disputa de intereses. De manera semejante ocurre en el proceso internacional de patrimonialización de la UNESCO, donde diversos países de distintos continentes, niveles de desarrollo e influencia políticoeconómica compiten por la elegibilidad de sus bienes en el reconocimiento internacional. Seguramente, este tema implicaría otra interesante investigación, ya que surgen interrogantes como ¿cuál debería ser la preocupación y responsabilidad común de la humanidad en dicha "puesta de valor"? O ¿cómo efectivamente se dan los procesos democráticos o participativos en la selección de un patrimonio en los diversos ámbitos político-administrativos? Temas y curiosidades diversas, que yacen después de que se tiene un mínimo de conocimiento acerca la temática.

Es necesario destacar que la principal distinción entre Patrimonio Mundial y Reserva de Biosfera corresponde a la perspectiva de puesta de valor: es que para el mantenimiento de dicho reconocimiento patrimonial internacional la Convención del Patrimonio es más rígida que las Reservas de Biosfera. De manera que el Patrimonio Mundial mira la conservación y gestión de sitios naturales y culturales excepcionales y además se propone ampliar la toma de conciencia para una mejor preservación del patrimonio, por intermedio de un instrumento jurídico vinculante. Por ello, el Comité del Patrimonio Mundial se reúne una vez al año para estudiar el estado de conservación de los sitios y bienes incluidos, involucrando tanto la Lista del Patrimonio Mundial como la Lista del Patrimonio Mundial en Peligro. Esta última se refiere a dar de baja un sitio si se considera que ha perdido su Valor Universal Excepcional (Salem \& Ghabbour, 2013). Asimismo, la Lista del Patrimonio Mundial en Peligro existe para informar a la comunidad internacional sobre las condiciones que amenazan las características por las que se ha inscrito un bien en la Lista del Patrimonio Mundial y para alentar acciones correctivas. 
Virginia Martins Fonseca;

Roberto Nicolas Bustos Cara

Las Reservas de Biosfera también pasan por una revisión periódica, cada diez años, donde deben presentar un informe acerca del cumplimento de los criterios generales de designación inicial y, en caso de no haberse atendido tales premisas y sugerencias en un plazo razonable, la zona puede dejar de ser considerada RB. También existe la posibilidad de que el mismo Estado la retire del MaB. Para Salem y Ghabbour (2013), la RB es implementada y adoptada por verdaderos creyentes en su concepto de modo independiente de todo compromiso internacional, y por tanto se implementa libre y voluntariamente, pero, solamente con el tiempo, el concepto podrá demostrar su validez y los beneficios que ofrece a las comunidades circundantes.

En este escenario, podemos presentar nuestra lectura de la Reserva de Biosfera Andino Norpatagónica [RBANP], en Argentina y; la Reserva de Biosfera Serra do Espinhaço [RBSE], en Brasil, considerando el reciente proceso de revisión periódica a las que fueron sometidas.
Patrimonialización de Áreas Naturales: prácticas vulnerables en las Reservas de Biosfera de Argentina y Brasil

\section{Prácticas vulnerables relacionadas a las Reservas de Biosfera Andino Norpatagónica (Argentina) y Serra do Espinhaço (Brasil)}

La RBANP surgió como posibilidad en mayo de 2005, bajo la coordinación de las instituciones: Administración de Parques Nacionales, Gobierno de la Provincia de Río Negro, Gobierno de la Provincia de Chubut, Comité de Integración Región de Los Lagos y el Parlamento Patagónico. Luego, en abril de 2007, la Administración de Parques Nacionales [APN], la Provincia de Río Negro y la Provincia de Chubut entregaron oficialmente a la oficina $\mathrm{MaB}$ Argentina el formulario del proyecto, con el objetivo de su presentación ante UNESCO, a través de su Cancillería; ésta declaró formalmente la creación de la "Reserva de Biosfera Andino Norpatagónica" en septiembre del mismo año (Figura 4).

Figura 4 e Figura 5 - Mapa de Localización RBANP e Mapa de Localización RBSE
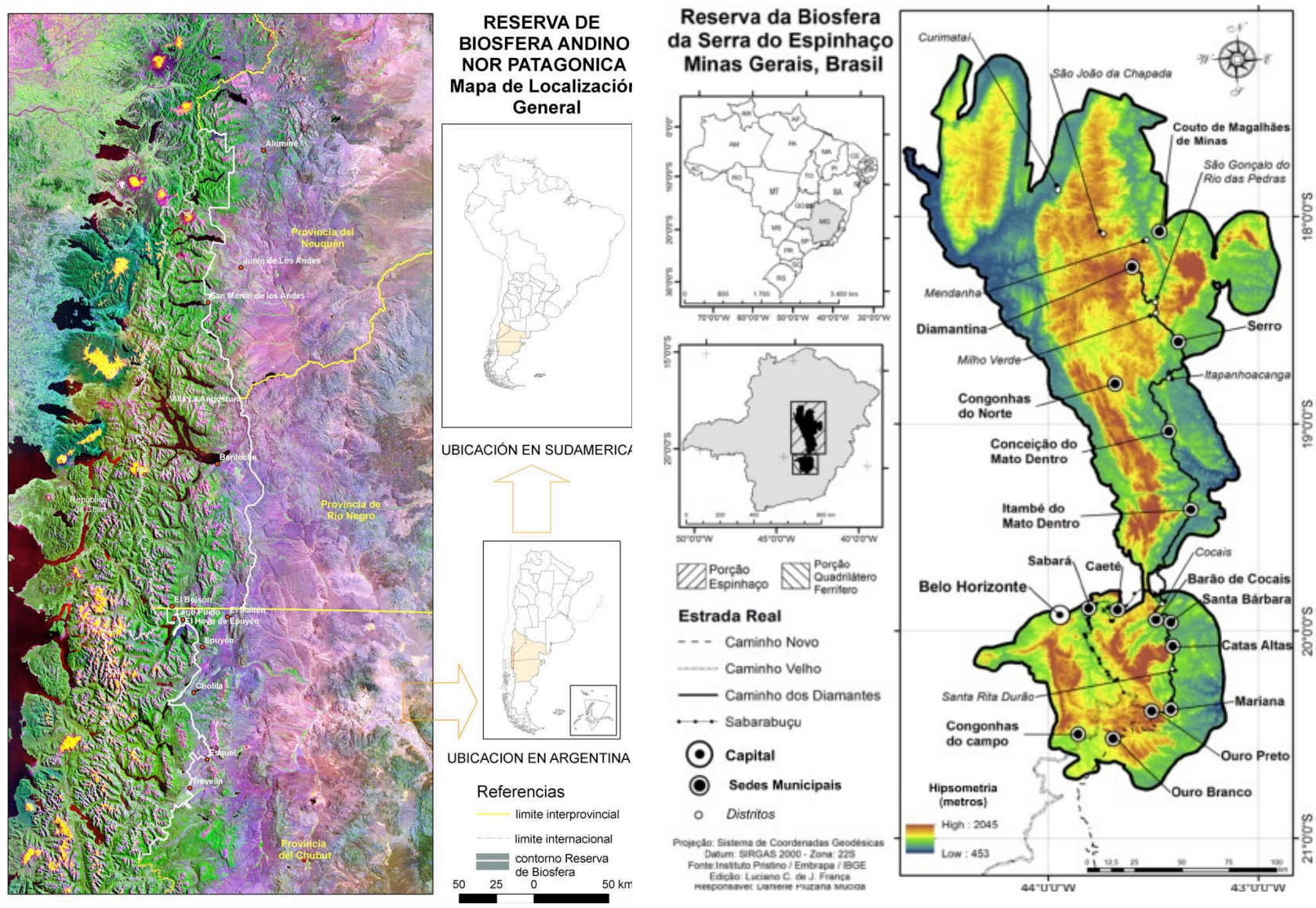

Fuentes: Pérez et al., 2017e Instituto Prístino (2015) 
Igualmente, la RBSE presentó su propuesta de creación en marzo de 2005, bajo la coordinación del Instituto Estadual de Florestas [IEF-MG] por intermedio de la Sociedade dos Amigos do Tabuleiro [SAT] involucrando instituciones públicas, dos universidades y el tercer sector (organizaciones no gubernamentales de medio ambiente). El 24 de junio del mismo año, fue reconocida por el Consejo Internacional de Coordinación del $\mathrm{MaB}$ (Figura 5

En el caso de la RBANP es importante subrayar que la Provincia de Neuquén, aunque ha apoyado la iniciativa de creación de la RB desde 2007, hasta 2017 no había incorporado territorio efectivamente, pues "no se logró avanzar con acciones concretas, sin embargo continúa abierto el espacio de intercambio y se espera -dada la relevancia del área para la conservación y desarrollo de la eco-región -, que se pueda avanzar hacia la zonificación efectiva de territorios colindantes al Parque Nacional Lanín" (Pérez, Caracotche, Pastor, Postler, Rafael, Salvaré \& Marqués, 2017, pp.18).

En el análisis de los informes referentes a la revisión periódica de ambas $\mathrm{RB}$ se consideraron los objetivos relativos a las tres funciones que deben cumplir. Así se pueden asociar los conceptos analizados de la siguiente manera: 1) Función de Conservación: Áreas Protegidas. 2) Función de Desarrollo: Turismo y Uso público; 3) Función de Apoyo Logístico: Procesos de Gestión y Gobernanza.

El formulario, establecido por la UNESCO para evaluar las RB, consta de más de 100 preguntasclaves. En este sentido, nos proponemos presentar algunos aportes de reflexión, condensando algunas informaciones en nueve temas del formulario: a) Información actualizada; b) Participación continúa de la población local en el trabajo de la RB; c) Estrategias de fortalecimiento de las capacidades colectivas para la gobernanza global de la RB; d) Función de Desarrollo; e) La industria del turismo; f) Las actividades económicas en la RB benefician a las comunidades locales; g) Iniciativas de desarrollo económico de la comunidad; h) Negocios locales y otras iniciativas de desarrollo económico; i) Gobernanza, Gestión de la Reserva de la Biosfera y Coordinación.

A continuación, se presenta una síntesis de las principales informaciones examinadas en dichos informes que podrán enriquecer algunos aportes acerca esta temática.

\section{a) Información actualizada:}

La RBANP comprende 2.321.786 has. en territorios cordilleranos de la Eco-región Valdiviana, que se extienden entre $39^{\circ} 06^{\prime}$ y los $43^{\circ} 29^{\prime}$ de latitud sur, incluyendo ámbitos de la Provincia de Río Negro (aprox. 470.000 has.); de la Provincia de Chubut (aprox. 435.400 has.) y de la jurisdicción de la Administración de Parques Nacionales (aprox. 1.416.360 has.). El Corredor Ecológico Andino Norpatagónico comprende un complejo mosaico de extensas áreas protegidas nacionales y provinciales, ya que el $71 \%$ de la superficie de la RBANP son. conformados por AP, considerando las áreas núcleos y áreas de amortiguación prioritarias de conservación (Pérez et al., 2017). La RBANP comprende una angosta faja de ambientes de alta montaña, bosques templados, pastizales y estepas subandinas, que constituye uno de los remanentes de bosques templados, en buen estado de conservación, más importante del planeta. Estos ambientes tienen un rol clave en la protección de altas cuencas, definen el extremo de distribución oriental de muchas de las especies más representativas de la Ecoregión (Nothofagus, Fitzroya, Austrocedrus, Araucaria), habiendo constituido refugios durante la última glaciación, y mantienen un área de gran integridad ambiental e importancia clave para la conservación de la misma en su conjunto; así como de la variabilidad genética de muchas de sus especies relevantes (Raffaele $e t$ al., 2014 citado en Pérez et al., 2017)

La RBSE comprende 3.076.457,80 has., entre $17^{\circ} 13$ y $44^{\circ} 41$ de latitud sur, en el Estado de Minas Gerais, incluyendo 94 municipalidades. El Corredor Ecológico Serra do Espinhaço mantiene AP nacionales, estaduales y municipales que representan poco más de $43 \%$ de la superficie de la RBSE, en que las AP conforman las áreas núcleos y áreas de amortiguación para conservación (Andrade, Martins \& Domingues, 2015). La RBSE representa la faja orogénica del precámbrico más extensa y continua del territorio brasileño, actuando como divisor de aguas entre la Cuenca del Rio São Francisco y los ríos que desaguan directamente en el Atlántico. Comprende tres ecosistemas brasileños de alta relevancia para conservación: Caatinga, Cerrado y Mata Atlántica, en lo cual los dos últimos son considerados los únicos botspots brasileños (Mittermeier, 2000, citado en Andrade et al., 2015), asimismo la cobertura vegetal predominante es el Campo Rupestre, valorado como una fito fisionomía del Cerrado, donde la concurrencia de área de biomas, sobre todo entre la Mata Atlántica y las diversas variaciones del Cerrado observan un alto grado de endemismo y biodiversidad.

Cabe aclarar que la Función de Conservación es relacionada a los objetivos que las RB deben cumplir, según directrices establecidas desde el proyecto de su concepción. En este sentido, las ideas relacionadas a los movimientos 
Virginia Martins Fonseca;

Roberto Nicolas Bustos Cara
Patrimonialización de Áreas Naturales: prácticas vulnerables en las Reservas de Biosfera de Argentina y Brasil ambientalistas, preservacionismo (Muir) y conservacionismo (Pinchot) cuando aplicados a las $\mathrm{RB}$ estarían relacionados, respectivamente, a las zonas núcleos (AP de protección estricta) y zonas de amortiguación (AP de protección de uso sostenible).

b) Participación continua de la población local en el trabajo de la RB:

El informe de la RBANP menciona que no hay espacios formales de participación en el ámbito de la RB para la población local, aunque hubo un intento de integrarla en las mesas y comité de gestión locales durante el desarrollo del Plan Estratégico Preliminar [PEP], donde se convocó y consultó a diferentes actores claves durante el desarrollo de los talleres de elaboración del plan hasta el 2010. Desde esa fecha se ha trabajado en los procesos de planificación de cada jurisdicción, para lo cual las autoridades convocaron a todos los actores directos de la reserva a participar en el ordenamiento de las diferentes zonas núcleo, amortiguamiento y transición (por ej. elaboración de planes de manejo en AP nacionales y provinciales, municipales; comités asesores para el ordenamiento territorial de la ley de bosques y la definición de proyectos de ejecución), según Pérez et al. (2017).

En el caso de la RBSE se observa que los foros de debate fueron definidos por otras instancias públicas responsables de las discusiones temáticas referentes a su área de actuación, como los comités de Cuencas Hidrográficas (Andrade et al., 2015); en el informe de la RBSE no hay un análisis propiamente dicho de la participación de la población local en la RB, pero sí de otros organismos.

En este sentido, aparece una seria fragilidad en lo que se refiere al tema en ambas RB, ya que dependerá exclusivamente de cada instancia político-institucional y en cómo se alcanzarán las representaciones en dichos consejos para efectivamente propiciar la participación continua de la población local. Además, es necesario reconocer que muchas veces tales consejos están conformados mayoritariamente por organismos estatales y no del tercer sector $\mathrm{y} / \mathrm{o}$ las comunidades locales. La participación de la población local no puede ser evaluada en la RB y menos aún en otras instancias, ya que no están en mira de evaluación de los órganos competentes, así como no nos pareció lo suficientemente consistente para afirmar el involucramiento de los actores locales en el proceso de gestión territorial.

c) Estrategias de fortalecimiento de las capacidades colectivas para la gobernanza global de la RB:

La RBANP menciona que no se han registrado en este territorio (Pérez et al., 2017). Con respecto a la RBSE indica que el fortalecimiento de las capacidades colectivas se lleva a cabo por intermedio del Plan de Acción del Comité Estadual, que, a partir de objetivos determinados por el Comité, son sugeridos protocolos de actividades a ser desarrolladas por las instituciones que mantienen representación en el consejo de la RBSE, considerando la finalidad de las mismas. (Andrade $e t$ al., 2015).

De esto se infiere que la única diferencia de la RBSE está en las acciones desarrolladas por dichas instituciones representativas del Comité, asociadas cómo resultados a los intereses del Comité. Visto así, este tipo de práctica está presente en la RBANP, cuando observamos otros ítems del formulario establecido por la UNESCO.

El informe no menciona acciones, del comité responsable de la gestión, que estimulen efectivamente una discusión tendiente a fortalecer las capacidades colectivas para la gobernanza global, dejando de lado iniciativas de protagonismo de posibles grupos interesados en proponer cambios colectivos y solidarios en el territorio.

\section{d) Función de Desarrollo:}

En la RBANP esta función se basa principalmente en el impulso creciente del desarrollo turístico, actividad que ya se perfila como una suerte de "monocultivo" productivo (Bondel, 2009, citado en Pérez et al., 2017). Dicha actividad representa, directa e indirectamente, más del $40 \%$ del movimiento económico de la región con un alto porcentaje de actores involucrados. Su deficiente planificación, estacionalidad, bajos niveles de redistribución y alta dependencia de variables macroeconómicas, se enlaza fuertemente con diferentes conflictos socioambientales presentes en el corredor en general y en sus principales ciudades en particular, ya que los centros de mayor desarrollo turístico concentran más del $80 \%$ de la población urbana en una porción muy pequeña del territorio, mientras el resto corresponde a la población verdaderamente rural -pobladores criollos y comunidades indígenas-que alcanza el 20\% el total (Bondel, 2009, citado en Pérez et al., 2017).

En la realidad brasileña, el escenario es muy distinto y camina a contramano del desarrollo turístico en la zona. El informe menciona que en más de $50 \%$ de las municipalidades involucradas en la RBSE, la extracción mineral constituye la principal actividad económica (Andrade et al., 2015), con el 50\% de las inversiones financieras, el 16\% de la industria automotriz y $15 \%$ de la industria siderúrgica. Es decir que solo estos tres sectores concentran el $80 \%$ de las inversiones en el territorio RBSE (Andrade et al., 2015, p. 163). Sin embargo, es el sector servicios y comercio el que emplea al $75 \%$ 
Virginia Martins Fonseca;

Roberto Nicolas Bustos Cara
Patrimonialización de Áreas Naturales: prácticas vulnerables en las Reservas de Biosfera de Argentina y Brasil de la población de la RBSE (Andrade et al., 2015, p. 164). Estos datos reflejan que, aún después de ciclos históricos de extracción de minerales, sea aquella la principal actividad en gran parte del territorio. Para Andrade et al. (2015), es muy importante que los gestores públicos y toda la sociedad comprendan cabalmente el ciclo de esta actividad a fin de planificar el futuro y garantizar el bienestar de las comunidades, ya que es sabido que la minería practicada en la Cadena del Espinhaço conlleva un alto grado de impacto en los ecosistemas naturales, en los manantiales hídricos y en la estructura social, urbana y rural.

La verificación, en ambas realidades, permite deducir cómo el contexto histórico de ocupación de estos territorios presenta una política institucionalizada en el desarrollo de la zona.

Se debe destacar que en Argentina el turismo siempre figuró como estrategia de desarrollo regional en la Patagonia Norte, asociado al reconocimiento de AP. En Brasil, en cambio, prevalecieron las estrategias aisladas de preservacionismo como solución para el uso desenfrenado de los recursos naturales y diversos impactos antrópicos.

\section{e) La industria del turismo:}

Ampliamente expuesto en el informe de la RBANP, el turismo, basado en las bellezas escénicas y en la integridad ambiental general del área, es un importante motor económico para la zona, con una creciente diversificación de la actividad; tanto en el área urbana como rural se registra un fuerte incremento de actividades con acceso a lugares remotos que dificultan las posibilidades de control, seguridad y monitoreo de los impactos, donde se han incorporado, en las actividades de uso público, nuevas modalidades acuáticas y terrestres que requerirán mayores esfuerzos de planificación, evaluación de los impactos y monitoreo, actualización de marcos reglamentarios que incluyan buenas prácticas y adecuación de la infraestructura. $\mathrm{El}$ informe destaca algunas apreciaciones del alcance de la actividad turística del corredor; según fuentes de las oficinas de turismo de los principales centros receptores de la zona en 2016, estiman que la visita superó el millón de turistas anuales. En tal escenario, el informe menciona que uno de los mayores desafíos que enfrenta el turismo en esta región es garantizar la sustentabilidad de las áreas protegidas y las actividades turísticas con buenos estándares de calidad. La conservación de los ambientes naturales requiere una adecuada articulación de la gestión del turismo, con la interacción de instituciones y organismos públicos y privados, para garantizar la perdurabilidad de los recursos. Paralelamente, el incremento de la oferta y demanda turística requieren prestar especial atención al ordenamiento territorial, procurando evitar la concentración y el desborde del flujo turístico en los centros receptores. Aparecen dos iniciativas en el informe en el ámbito de la RB relacionadas al turismo:

1. Programa de Desarrollo de Corredores Turísticos: con el objetivo de incrementar el gasto turístico de las AP y sus destinos asociados, mediante el apoyo a la estructuración de productos turísticos, fortalecimiento institucional y mejora de la gestión ambiental que, en esta región, es el Corredor de Los Lagos, comprendiendo prácticamente al ámbito de toda la RBANP. En este caso, además de los fondos invertidos en mejoramiento de la infraestructura vial, de puertos y muelles, se han financiado proyectos de renovación de acceso a las áreas, señalización, senderos, grupos sanitarios, centros de visitantes, y sub centrales de atención de emergencias;

2. Programa Nacional Senderos de Argentina Proyecto Huella Andina: Este proyecto fue ideado en 2009 en el marco de la RBANP, con el objetivo de crear el primer sendero de circuito extenso de la Argentina. Para ello se identificó un recorrido troncal, en general de baja-media dificultad, que permitiera unir mediante senderos señalizados, un total de aproximadamente $560 \mathrm{~km}$, con 42 etapas, desde la zona del lago Aluminé en la Provincia del Neuquén, hasta el área del lago Baguilt en Trevelin, Provincia de Chubut. El mismo permite visitar los parques nacionales que conforman la RB -Lanín, Nahuel Huapí, Arrayanes, Lago Puelo y Los Alerces -además de reservas provinciales y territorios fiscales y privados (Pelozo et al., 2016, citado en Pérez et al., 2017).

En el caso de la RBSE, aunque expone informaciones válidas acerca la actividad turística en la zona, se observa la fragilidad de dicha estrategia económica, principalmente en áreas naturales protegidas. Destaca el turismo en una perspectiva de ámbito provincial. Los datos estadísticos reflejan que, para los turistas, la imagen de Minas Gerais [MG], equivale a gastronomía (más del 30\%) y a sus habitantes $(13 \%)$, imprimiendo una marca fuertemente cultural (Turismo Cultural), con casi el $50 \%$ de interés por parte de los visitantes (Andrade et al., 2015). Existen Programas de Fomento al Turismo en el Estado de Minas Gerais, que impactan la zona de la RBSE: 
Virginia Martins Fonseca;

Roberto Nicolas Bustos Cara
Patrimonialización de Áreas Naturales: prácticas vulnerables en las Reservas de Biosfera de Argentina y Brasil
1. Programa de Regionalización del Estado de MG, donde se han institucionalizado Circuitos Turísticos, se trata de un conjunto de municipios de una misma región, con afinidades culturales, sociales y económicas que se unen para organizar y desarrollar la actividad turística regional, con el propósito de consolidar una identidad regional. En MG, actualmente, existen 45 Circuitos que involucran 470 municipios (más del 55\% del Estado). En el territorio de la RSBE, se ubican 8 Circuitos Turísticos (Andrade et al., 2015,);

2. Destinos Inductores de Desarrollo Turístico Regional. Constituye una estrategia del Gobierno Federal, que identificó 65 destinos en el país, caracterizados por la infraestructura y atractivos calificados, capaces de proyectar el núcleo receptor en la distribución de flujos turísticos. Son 4 los Destinos Inductores de Minas Gerais, en que se destacan los municipios de Ouro Preto y Diamantina, situados en la RBSE (Andrade et al., 2015);

3. Proyecto Estrada Real, en él el Instituto, de mismo nombre, vinculado al Sistema FIEMG, tiene como objetivo organizar, fomentar y administrar un antiguo camino, de más de 300 años, con alrededor de $1600 \mathrm{~km}$ de extensión, recorriendo principalmente el Estado de Minas Gerais, y otros municipios de los Estados de São Paulo y Rio de Janeiro. Este trayecto constituía la vía de salida de las riquezas minerales extraídas por la Corona Portuguesa en el período colonial del país, asimismo como ruta de abastecimiento a las ciudades de explotación de oro y diamantes (Andrade et al., 2015, p. 173). En este sentido, la Estrada Real suma 57 municipios del territorio de la RBSE (Andrade et al., 2015).

El análisis de los informes técnicos de las RBANP y RBSE se refieren al turismo como una "industria", que, vinculada a las áreas naturales, particularmente en las ANP, adquiere una connotación que el título mundial de Reserva de Biosfera asume un carácter diferencial para la proyección de dicho "producto turístico".

f) Las actividades económicas en la RB

benefician a las comunidades locales:

El informe menciona que actualmente no existen actividades económicas promovidas desde la RBANP que beneficien directamente a las comunidades locales (Pérez et al., 2017), en cuanto el informe de la RBSE indica que Minas Gerais es el mayor estado de actividad extractiva del país, responsable del $53 \%$ de la producción de minerales metálicos y del 29\% de empresas mineras en general (Andrade et al., 2015). Dentro de los diez municipios que más reciben la Compensación Financiera por la Exploración de Recursos de Minería [CFEM] en el Estado, nueve están dentro de la RBSE. La CFEM distribuye $12 \%$ en ámbito federal, $23 \%$ al Estado y $65 \%$ a la municipalidad. Los recursos deben ser destinados a proyectos de infraestructura, mejora de la calidad ambiental, salud y educación, ya que no pueden ser asignados a pagos de deuda, o salarios de personal-funcionarios públicos, lo que impacta directa o indirectamente- las comunidades (Andrade et al., 2015).

En la práctica, hasta el momento las RB no benefician directamente a las comunidades locales. Considerando la complejidad de dicha afirmación, optaremos por continuar el análisis de ambos informes para hacer aportes más precisos, de esta perspectiva, al final del capítulo.

g) Iniciativas de desarrollo económico de la comunidad:

Si bien en el PEP de la RBANP se incluyen algunas estrategias para la innovación económica, cambio y adaptación dentro de la RB, aún no se han implementado (Pérez et al., 2017); en el informe de la RBSE se menciona que en Minas Gerais existe el Programa de Apoyo a Competitividad de Clústeres como estrategia para este cuestionamiento (el clúster se define como un conjunto de empresas que participan de un mismo negocio en una determinada región geográfica, que operan bajo un régimen de cooperación y generan competitividad colectiva). El territorio de la RBSE involucra a dos ramas de actividad, ambas exclusivamente en la Región Metropolitana de Belo Horizonte: Biotecnología y Cuero (calzados y marroquinería) (Andrade et al., 2015).

Este tema, como el anterior, será tratado más adelante, y cabe la pregunta: ¿A qué tipo de intereses socioeconómicos deben proteger las RB?

h) Negocios locales y otras iniciativas de desarrollo económico en la RB:

También se considera que en el PEPRBANP se incluyen algunas estrategias para la innovación económica, cambio, y adaptación dentro de la RB, que sin embargo no se han implementado aún (Pérez et al., 2017). La RBSE menciona que el desafío está en concertar un desarrollo económico con sustentabilidad (Andrade et al., 2015, p.208), contemplando los impactos de los sectores de minería e industria en la zona.

Igualmente, este tema está asociado al análisis crítico de los dos últimos ítems analizados: 
Virginia Martins Fonseca;

Roberto Nicolas Bustos Cara
Patrimonialización de Áreas Naturales: prácticas vulnerables en las Reservas de Biosfera de Argentina y Brasil ¿cómo afecta a la población local la función de desarrollo de las RB?

i) Gobernanza, Gestión de la Reserva de la Biosfera y Coordinación

El informe menciona que la RBANP, a casi 10 años de su designación formal, no logra una inserción fuerte, continuada y amplia como espacio de apoyo a la gestión y concertación interjurisdiccional e interinstitucional en el ámbito del corredor (Pérez et al., 2017). En este sentido, desde el punto de vista político, la toma de decisiones en el territorio de la RB se hace desde cada organismo jurisdiccional. No se ha mantenido activa la Mesa Ejecutiva del Comité de Gestión, ni se constituyó la Mesa Ampliada, que permitiría llevar a cabo políticas públicas acordadas en los distintos ámbitos de la RB. El proceso de trabajo mostró dificultades para conformar espacios específicos en la RBANP, que estructurarían la participación comunitaria; se trabajó entonces a través de la articulación con ámbitos sectoriales activos en el territorio y mediante convocatorias por temáticas particulares. La experiencia, transitada durante 10 años, señaló que es necesario reformular el espacio de gestión de la RBANP con el fin de mejorar la articulación de las decisiones políticas y técnicas; asî como focalizar el núcleo de temáticas centrales y acciones operativas a desarrollar en conjunto en el marco de la misma (Pérez et al., 2017).

Por lo tanto, se acordó en el ámbito de la Mesa Ejecutiva, y para una mayor operatividad territorial directa, que las autoridades jurisdiccionales estén representadas a nivel de Direcciones, Subsecretarías o Secretarías de Estado (en el marco de lo definido para su constitución en 2008), a través de un Acta de dicha Mesa y cuyas funciones sean convocar una Mesa Ampliada con otras autoridades del territorio. En el caso de los territorios dependientes de la APN, se incorporó la representación de la Dirección Regional Patagonia Norte [DRPN] y se mantendrá la representación de los Intendentes de los cuatro parques nacionales incluidos en la RBANP, y en forma rotativa como hasta el presente. En este sentido se resolvió ampliar la conformación de la Secretaría Técnica, que trabaja en articulación directa con esa Mesa Ejecutiva y en el territorio, a través de la incorporación de nuevos actores como los Municipios (con territorio incluido en $\mathrm{RB}$ ) y el sector científico técnico. Esto se orienta a multiplicar la cantidad de actores directamente involucrados en la gestión y a fortalecer los vínculos con los gestores territoriales directos; así como a incorporar un consejo con representación de las instituciones de ciencia y técnica como parte de un espacio de asesoramiento directo para la RBANP (Pérez et al., 2017). En tal sentido, se redefinen algunos aspectos con relación a la estructura, rangos de representación y funciones de la Mesa Ejecutiva de las máximas autoridades jurisdiccionales del Comité de Gestión y composición de la Secretaría Técnica de la RBANP.

La RBSE coordinada por la Comisión Brasilera para el Programa MaB -COBRAMaB, se vincula con el Ministerio del Medio Ambiente del Gobierno Federal, en este caso la gobernanza está apoyada en tres marcos legales: 1) SNUC (Ley Nacional $n^{\circ} 9.985 / 2000$, cuyo capítulo XI está dirigido al tema de las RB; 2) Decreto Estadual n44.281/2006, que según directrices del SNUC, establece el Comité Estadual de la RSBE, define sus atribuciones, las estrategias para alcance de los objetivos propuestos y la estructura del Comité; y 3) Reglamento Interno del Comité Estadual: que determina el rol de los miembros representantes de las diversas instituciones para reglamentar: objetivos del comité; competencias del mismo considerando su carácter consultivo, normativo y deliberativo en gestión de la RBSE; composición de miembros del poder público y sociedad civil; deberes de cada miembro, formas de gestión y atribuciones de la Coordinación, ViceCoordinación y Secretaría Ejecutiva y, funcionamiento de las reuniones y otras participaciones (Andrade et al., 2015). Actualmente, el Comité Estadual de la RBSE está compuesto por 21 miembros activos, donde la equipe de Coordinación, Vice-Coordinación y Secretaria Ejecutiva son las instituciones: Pontificia Universidad Católica de Minas Gerais, Fundação Biodiversitas y Asociación Cultural y Ecológica Lagoa do Nado (Andrade et al., 2015). El Comité Gestor de la RBSE posee oficina en el Centro de Integración para la Sustentabilidad Ambiental [CISAL] en la PUCMinas. Se trata de un laboratorio de práctica profesional y desarrollo tecnológico y científico asociado al Departamento de Ciencias Biológicas que aporta al Comité un equipo de docentes, estudiantes becarios y pasantías universitarias. La Plenaria cuenta con el apoyo técnico de funcionarios del ACELN, Instituto Cidade y Biodiversitas (representantes del tercer sector); SINDIEXTRA y FIEMG (apoyo financiero y técnico a proyectos de la RBSE), SEMAD (FEAM, IEF e IGAM) e ICMBIO (Andrade et al., 2015, p. 246). Según el informe, el acuerdo es el libre acceso a los documentos de referencia del Programa $\mathrm{MaB}$ por parte de los representantes del poder público del Comité Estadual de la RBSE, de modo de evitar una discontinuidad política, común en la transición de los gobiernos, lo que contribuye a generar un mayor equilibrio y autonomía en la gestión de la RBSE (Andrade et al., 2015).

Del análisis se puede observar que los cambios propuestos en la RBANP se asemejan a la actual estructura de la RBSE, reflejando una fragilidad en el tema del involucramiento de la población local en 
Virginia Martins Fonseca;

Roberto Nicolas Bustos Cara
Patrimonialización de Áreas Naturales: prácticas vulnerables en las Reservas de Biosfera de Argentina y Brasil un debate legítimo, acerca de cuáles serían las posibilidades de integración de la temática del "Hombre y la Biosfera", en cuán efectiva sea la estrategia de una ecología política que aún está en construcción, mismo como herramienta con más de 40 años de existencia.

Reforzamos, en este sentido, el tema de la ecología política, considerando los interrogantes anteriormente planteados: ¿Cómo afecta a la población local la función de desarrollo de las RB? ¿A qué tipo de intereses socioeconómicos deben proteger las RB? ¿En qué consiste la afirmativa de que las RB no benefician directamente a las comunidades locales?

\section{Consideraciones finales}

La temática de los procesos de patrimonialización está directamente relacionada con la óptica de la globalización, que Santos (1996) interpreta como el intermediario entre el mundo y el individuo, que justifica y transforma el "lugar" en algo "universal", para toda la humanidad, entonces la denominación de "reserva" excluye la idea de lo "local". El autor lo considera como conflictos que se suceden en torno a la explotación y al acceso de los recursos señalando muy claramente quienes serán y quedarán excluidos. Se trata de una naturaleza unificada por la historia a servicio de los actores hegemónicos, donde la técnica pasó a ser la mediación fundamental del hombre con su entorno, puesto que la técnica es la base de la realización mundial como totalidad empírica y esta solamente es alcanzada por intermedio de los lugares, en la medida que los lugares expresan la funcionalidad del mundo (Santos, 1995). En este sentido, en el caso de la RBSE, uno de los principales actores intervinientes en el territorio es un actor económico que explota fuertemente en la zona los recursos minerales y que, indudablemente, no tiene aproximación alguna con la población local. Ya en la RBANP, se puede asociar la globalización a la patrimonialización y, esta, al desarrollo del turismo.

Puesto que inferimos según análisis hechos en los informes, entendemos que la función de desarrollo de las RB afecta a la población local a partir del momento que consolida la puesta de valor en ámbito internacional de las AP sin la efectiva atención a cuáles serían los reales conflictos existentes entre tales actores. Asimismo, cuando buscamos comprender a qué tipo de intereses socioeconómicos deben proteger las RB, no notamos en los informes cómo los consejos responsables por la gestión del territorio en ambas las $\mathrm{RB}$ estimulan las comunidades locales para posibles desarrollos económicos en armonía con la naturaleza. Peor, en el caso de la RBSE, son las minerías las mantenedoras en el desarrollo de proyectos de extensión e investigación lo que resulta curioso de cuáles serían los resultados de tales proyectos. Por fin, cuando afirmamos que las RB no benefician directamente a las comunidades locales, la hacemos por entender que no solo las comunidades locales no están enteradas de que es una RB, como principalmente tales comunidades no entienden como dicha puesta de valor internacional puede contribuir en su mejoría de cualidad de vida, incluso con oportunidades de trabajo dignas.

\section{El discurso ecológico tiene substituido el espacio concreto de la práctica social del vivido, aquel del habitar en el sentido amplio.... se pasa del vivido al abstracto para proyectar esta abstracción al nivel del vivido. En este sentido, la naturaleza vira signo, y se torna estrategia y política (Carlos, 1994 citado en Santos, 1995, p. 149).}

Más que nunca, la comprensión de los enunciados de la ecología política son importantes y, en el discurso político-institucional de las RB, deben ser evaluados desde una perspectiva simbólica $y$ estratégica, con una actitud crítica, ya que ineludiblemente es el Estado es responsable directo en el establecimiento de líneas generales macro políticas de la gestión ambiental de sus territorios; allí es prioritario el intento de reformular una visión de la ecología política latinoamericana que otorgue a "lo político" un lugar central, que al mismo tiempo dé cuenta de su porosidad y de su carácter contradictorio (Alimonda, 2017, p. 45).

$\mathrm{El}$ ingreso en los procesos de patrimonialización de ambas categorías (RB y Patrimonio Mundial) implican compromisos (e intereses) distintos para los actores involucrados. Allí el Estado debe posicionarse claramente generando un balance en sus políticas de desarrollo económico, inversiones privadas (y multinacionales) y preservación ambiental, teniendo en cuenta los conflictos presentes en una estructura donde se dirimen prioridades y conveniencias.

En este sentido los organismos gubernamentales deben articular con la sociedad y, en especial, con los pueblos indígenas y comunidades locales [PI\&CL] a lo largo de todo el proceso, si desean garantizar la efectividad de las acciones, puesto que son estos grupos los que mantienen el conocimiento especializado fundamental en la gestión territorial y de los recursos de las áreas a proteger, siendo esencial el involucramiento de los mismos como sujetos activos. Igualmente, para estos pueblos existe el reto del empoderamiento mediante conceptos e instrumentos de preservación, con el fin de lograr una participación más articulada en las negociaciones que involucran territorios y recursos, ya que estos no son 
Virginia Martins Fonseca;

Roberto Nicolas Bustos Cara
Patrimonialización de Áreas Naturales: prácticas vulnerables en las Reservas de Biosfera de Argentina y Brasil efectivamente informados de los objetivos de la puesta de valor internacional.

Finalmente, como categorías que sustentan las prácticas, están las ONG del Tercer Sector y universidades que promueven proyectos y actividades relacionadas a la preservación ambiental y/o del patrimonio que, de alguna manera, están más próximas a la población. Estas deberían comprender que el mayor reto, en tal contexto, es contribuir a los procesos de organización política. Los investigadores deberían pronunciarse como críticos de acciones institucionales que están en desacuerdo de la legislación e instrumentos técnicos además generar las condiciones de amparo de las necesidades e intereses de la comunidad. Cabe aclarar que tales intereses pueden estar relacionados a la preservación, y en la compatibilización del uso de los recursos en vistas a su propia supervivencia: un ciclo virtuoso o vicioso, según los actores protagonistas.

En la mayoría de los casos, se observa una incompatibilidad de acciones, intereses y fuerzas motoras entre las sociedades y el discurso teórico, legal, técnico, metodológico (todos de base institucional y relacionados con la protección del patrimonio), que dificultan las propuestas de acciones estratégicas locales, nacionales e internacionales tan necesarias para los pueblos involucrados como para la humanidad beneficiada en dicho logro de activación patrimonial. Aunque el escenario desafiante de articulación demande tiempo, trabajo, diálogo, negociaciones y acuerdos, es necesario idealizar una convergencia de acciones acertadas, justas y equitativas que resulten en soluciones integradas que logren atender los verdaderos intereses colectivos o, ¿sería mejor adoptar el término inter-relacionados, cuando nos referimos a los pueblos y la naturaleza? En este sentido, cabe mencionar dos aspectos, primordialmente:

$1^{\circ}$ ) Pese a que los procesos de patrimonialización reflejen disparidades importantes en cuanto al discurso, como construcción subjetiva de calidad y mérito imprescindible para el reconocimiento de determinado territorio como de Valor Universal Excepcional, es innegable que tal procedimiento le otorga un contorno de legalidad, incluso en el ámbito internacional, a la necesidad de cuidado y preservación de determinada región. Esto conduce al segundo aspecto, en el que pesan los diversos intereses mayoritariamente económicos, y se refiere al uso del territorio;

$\left.2^{\circ}\right)$ En este sentido, se observa en cuanto a la temática de los conflictos entre las comunidades locales y los organismos gestores de los territorios, al menos en los discursos, está creciendo el intento de proporcionar un involucramiento de los actores sociales ante la preocupación latente de preservar o conservar determinado ambiente natural para lograr un equilibrio socio-ambiental. Pero mismo en el discurso ideológico existen distintos juegos de poder e intereses, incluso en el turismo como sector productivo.

Es importante que el profesional del turismo se comprometa seriamente con el desarrollo de la actividad y que exponga un discurso diferente al institucional. Más allá de que el turismo presenta impactos negativos esta actividad significa el mal menor para el patrimonio. Por lo tanto, inferimos que mismo cuando el patrimonio asume la concepción de producto turístico para ganar merito en el escenario mercadológico de la actividad, cuando comparado con otros sectores para los cuales están pautadas formas de consumo cada vez más irracionales, el turismo se presenta como una alternativa más equilibrada de uso del territorio patrimonializado.

A partir del reconocimiento de los sitios patrimonializados como producto turístico, es necesario repensar estrategias de posicionamiento mercadológico en lo cual el diferencial debe ser la adopción de políticas integradoras y de apoyo para que los PI\&CL efectivamente sean los principales inversores de la actividad, lo que lamentablemente parece estar lejos de ocurrir. Sin embargo, los profesionales deben tomar conciencia y asumir el compromiso acerca la necesidad de sensibilizar a la sociedad, de manera general, como si fuera una rebelión silenciosa y diferenciada, (a través de las redes sociales, por ejemplo), para ayudar a unificar ideologías y sinergias, y promover consecuentemente una transformación en la realidad mundial cambiando prácticas vulnerables. Santos (2000) mencionaba que el mundo puede ser visto desde otra óptica que no sea el de la "fábula", cuando se habla de los medios de la información y comunicación.

Además, aunque los principios teóricos tanto del turismo como de las AP dependieran del involucramiento de las comunidades, hay que comprender que los principios solo tendrán alcance si preexiste el reconocimiento amplio de que todo esto está relacionado al sentido de gobernanza de los territorios. Esto significa adoptar como referencia que el dominio (tenencia) del territorio debe contar con procesos de gobernanza incluso por los PI\&CL.

\section{Referências bibliográficas}

Alimonda, H. (2017). En clave de sur: la Ecología Política Latinoamericana y el pensamiento crítico. En H. Alimonda, C. Toro, \& F. Martín (Coord.). Ecología política latinoamericana: pensamiento crítico, diferencia latinoamericana y rearticulación epistémica (pp. 
Virginia Martins Fonseca;

Roberto Nicolas Bustos Cara
Patrimonialización de Áreas Naturales: prácticas vulnerables en las Reservas de Biosfera de Argentina y Brasil
33-49), Buenos Aires, México: CLACSO, Universidad Autónoma Metropolitana, Ciccus. Recuperado el 21 de octubre de 2020,

http://biblioteca.clacso.edu.ar/clacso/gt/2017 1030111951/GT Ecologia politica Tomo I.p df

Almirón, A., Bertoncello, R. \& Troncoso, C. A. (2006). Turismo, patrimonio y territorio: Una discusión de sus relaciones a partir de casos de Argentina. Estudios y Perspectivas en Turismo, 15 (2), 101-124. Recuperado el 21 de octubre de 2020, http://www.scielo.org.ar/pdf/eypt/v15n2/v1 5n2a01.pdf

Andrade, M. A., Martins, C. S. \& Domingues, S. A. (Org.) (2015). Reserva da Biosfera da Serra do Espinhaço. Primeira. Revisão Periódica (20052015), Belo Horizonte, Minas Gerais: MaBUNESCO. Recuperado el 21 de octubre de 2020,https://issuu.com/reservadabiosferada serradoespinhaco/docs/rbse 1 revis o peri dica portug

Bardin, L. (2011). Análise de conteúdo. São Paulo: Edições 70.

Bertoncello, R. (2010). Turismo y patrimonio, entre la cultura y el negocio. En M. T. D. Paes \& M. R. S. Oliveira, Geografia, turismo e patrimônio cultural (pp. 33-53). São Paulo: Annablume.

Bertoncello, R. \& Troncoso, C. (2018). Vínculos entre patrimonio natural y turismo: una revisión para el caso argentino. Pasado Abierto, 4 (8). Recuperado el 21 de octubre de

2020 ,

https://fh.mdp.edu.ar/revistas/index.php/pas adoabierto/article/view/2867/3080

Bustos, R. N. \& Pinassi, A. (2017). The development and management of territorial heritage: the recent experience of Argentina. En Manero, F. \& García, J. L. Territorial Heritage \& Spatial Planning. A Geographical Perspective. The Global Law Collection (pp. 277-298). Navarra: Thomson Reuters.

Costa, E. (2014). Fundamentos de uma emergente patrimonialização global. GEOGRAFIA, 39 (2), 241-256. Recuperado el 21 de octubre de 2020, http://www.periodicos.rc.biblioteca.unesp.br/i ndex.php/ageteo/article/view/9318

Da Matta, R. (1981). Você tem cultura?. Jornal da Embratel. Recuperado el 21 de octubre de 2020, https://docplayer.com.br/107663256Voce-tem-cultura-1-roberto-damatta$\underline{\text { antropologo.html }}$
Di Méo, G. (2014). Processos de patrimonialização e construção de territórios. Geosaberes: Revista De Estudos Geoeducacionais, 5 (1), 3-23. Recuperado el 21 de octubre de 2020, http://www.geosaberes.ufc.br/geosaberes/a rticle/view/292

Instituto Prístino (2015). Atlas digital geoambiental da Reserva da Biosfera da Serra do Espinhaço. Recuperado el 21 de octubre de 2020, https://www.institutopristino.org.br/atlas/

Martins Fonseca, V. (2018). Patrimonialización de la naturaleza en Argentina y Brasil: reserva de biosfera y parque nacional como discurso global y práctica local. (Tesis doctoral en Geografía). Universidad Nacional del Sur, Argentina. Recuperado el 21 de octubre de 2020, http://repositoriodigital.uns.edu.ar/handle/12 $\underline{3456789 / 4492}$

Moraes, R. (1999). Análise de conteúdo. Revista Educação, 22 (37), 7-32. Recuperado el 21 de octubre de 2020, http://cliente.argo.com.br/ $\sim$ mgos/analise de conteudo moraes.html

Prats, L. (1998). El concepto de patrimonio cultural. Política y Sociedad, 27, 63-76. Recuperado el 21 de octubre de 2020, http://revistascientificas.filo.uba.ar/index.php CAS/article/view/4709/4206

Prats, L. (2005). Concepto y gestión del patrimonio local. Cuadernos de Antropología Social, (21), 17-35. Recuperado el 21 de octubre de 2020 , https://www.redalyc.org/pdf/1809/18091391 $\underline{0002 . p d f}$

Pérez, A., Caracotche, S., Pastor, M., Postler, V., Rafael, M., Salvaré, F. \& Marqués, B. (Coord.) (2017). Primera Revisión de la Reserva de Biósfera Andino Norpatagónica. Patagónia, Argentina. Recuperado el 21 de octubre de 2020,

https://www.biosferapatagonica.org/wpcontent/uploads/2017/12/RBANP InformeRevision-Periodica 2007-2017.pdf

Salem, B. B. \& Ghabbour, S. I. (2013). Joint biosphere reserves and world heritage sites. World heritage review, (70), 24-33. Recuperado el 21 de octubre de 2020, https://unesdoc.unesco.org/ark:/48223/pf0 000225631_spa

Santos, J. L. (1984). 0 que é cultura. São Paulo: Brasiliense. Recuperado el 21 de octubre de 2020,

https://ayrtonbecalle.files.wordpress.com/201 4/03/o-que-c3a9-cultura-jose-luiz-dos$\underline{\text { santos.pdf }}$

Santos, M. (1995). A questão do meio ambiente: desafios para a construção de una 
Virginia Martins Fonseca;

Roberto Nicolas Bustos Cara
Patrimonialización de Áreas Naturales: prácticas vulnerables en las Reservas de Biosfera de Argentina y Brasil perspectiva transdisciplinar. Anales de Geografia de la Universidad Complutense. Norteamérica, 15, 695-705. Recuperado el 21 de octubre de 2020, http://revistas.ucm.es/index.php/AGUC/arti cle/view/AGUC9595220696A

Santos, M. (1996). A natureza do espaço: Técnica e tempo, razão e emoção. São Paulo: Hucitec.

Santos, M. (2000). Por uma outra globalização: do pensamento único à consciência universal. Rio de Janeiro: Record.

Scifoni, S. (2003). Patrimônio mundial: do ideal humanista à utopia de uma nova civilização. GEOUSP - Espaço e Tempo, 14, 77-88. Recuperado el 21 de octubre de 2020, http://www.geografia.fflch.usp.br/publicacoes LGeousp/Geousp14/Geousp 14 Scifoni

Scifoni, S. (2004). A Unesco e os patrimônios da humanidade: valoração no contexto das relações internacionais. En II Encontro nacional de Pós Graduação e Pesquisa em Ambiente e Sociedade, Indaiatuba (pp. 1-17). Campinas: ANPPAS. Recuperado el 21 de octubre de 2020, http://www.anppas.org.br/encontro anual/en contro2/GT/GT13/simone scifoni.pdf.

UNESCO (1954). Convención para la Protección de los Bienes Culturales en caso de Conflicto Armado y Reglamento para la aplicación de la Convención 1954. Recuperado el 21 de octubre de 2020, http://portal.unesco.org/es/ev.php-

URL ID=13637\&URL DO=DO TOPIC\&U $\underline{\mathrm{RL} \text { SECTION=201.html }}$

UNESCO (1972). Convención sobre la Protección del Patrimonio Mundial Cultural y Natural. Recuperado el 21 de octubre de 2020, http://portal.unesco.org/es/ev.php- $\underline{\text { RL ID }=13055 \& U R L \text { DO=DO TOPIC\&UR }}$ L SECTION=201.html

UNESCO (2019). World Heritage List Statistics. Recuperado el 21 de octubre de 2020, http://whc.unesco.org/en/list/stat/

UNESCO \& MaB. (1971). Consejo Internacional de Coordinación. Final Report First Session. Colección de Informes del MaB. Recuperado el 21 de octubre de 2020, http://npshistory.com/publications/mab/une sco-mab-report/1.pdf

UNESCO \& MaB. (1985). Consejo Internacional de Coordinación. Informe Final de Octava Reunión. Colección de Informes del MaB. Recuperado el 21 de octubre de 2020, http://unesdoc.unesco.org/images/0006/000 661/066164sb.pdf

UNESCO \& MaB (1996). Reservas de Biosfera: La Estrategia de Sevilla y el Marco Estatutario de la Red Mundial. Recuperado el 21 de octubre de

2020 , http://unesdoc.unesco.org/images/0010/001 038/103849sb.pdf

UNESCO \& MaB (2008). Plan de Acción de Madrid para las Reservas de Biosfera (2008-2013). Recuperado el 21 de octubre de 2020, http://unesdoc.unesco.org/images/0016/001 $\underline{633 / 163301 \text { s.pdf }}$

UNESCO \& MaB (2019). Directory of the World Network of Biosphere Reserves. Recuperado el 21 de octubre de 2020 ,

http://www.unesco.org/new/en/naturalsciences/environment/ecologicalsciences/biosphere-reserves/world-networkwnbr/wnbr/

Yin, R. K. (2010). Estudo de caso: planejamento e métodos. Porto Alegre: Bookman.

\section{Notas}

i Resultados parciales de la tesis doctoral financiada por la CAPES (2012-2015) para la autora bajo la dirección del autor y, concluida en diciembre de 2018.

ii Datos obtenidos de Martins Fonseca, 2018 y actualizados para publicación de esto trabajo científico en PatryTer. iii Cada Reserva de Biosfera tiene como objetivo cumplir tres funciones complementarias: conservar recursos genéticos, especies, ecosistemas y paisajes; estimular el desarrollo sustentable, social y económico y apoyar proyectos demostrativos, tanto de investigación como de educación, en el área de medio ambiente. 